\section{P2-499 A SILENT PUBLIC HEALTH CRISIS: THE BURDEN OF UNTREATED CARIES AND DENTAL INFECTIONS IN THE PHILIPPINES NATIONAL ORAL HEALTH SURVEY 2006}

doi:10.1136/jech.2011.142976m.26

${ }^{1} \mathrm{H}$ Benzian, ${ }^{2} \mathrm{~B}$ Monse, ${ }^{3} \mathrm{~W}$ van Palenstein Helderman. ${ }^{*}$ The Health Bureau Ltd, Haversham, UK; ${ }^{2}$ Fit for School Inc., Manila, The Philippines; ${ }^{3}$ Department of Global Oral Health, Radboud University, Nijmegen, The Netherlands

Introduction The 2006 National Oral Health Survey in the Philippines was part of an advocacy strategy for increased attention for the neglected state of child oral health in the country. The survey assessed the oral health status of 6- and 12-yr-old children in a representative national sample.

Methods Survey of 2030 6-yr-old and 2022 12-yr-old children, using WHO Basic Methods (WHOBM $4^{\text {th }}$ edition) and the new PUFAindex. Inclusion of a subsample of 242 12-yr-old children for assessment of backward comparability between the $3^{\text {rd }}$ edition of the WHOBM used in the previous survey (1998) and the $4^{\text {th }}$ edition WHOBM.

Results $97 \%$ of 6 -yr-old children had caries (mean dmft 8.4, d=8.0, $\mathrm{m}=0.4, \mathrm{f}=0$ ), $85 \%$ live with dental infection (mean pufa 3.4 ) and $20 \%$ reported pain when examined. 12-yr-old children had $82 \%$ caries prevalence (mean DMFT 2.9, $\mathrm{D}=2.7, \mathrm{M}=0.2, \mathrm{~F}=0$ ), $56 \%$ prevalence of pulp involvement (mean PUFA 1), and $16 \%$ reported pain when examined.

Conclusion The burden of dental decay is very high and has remained virtually unchanged since 1998, indicating a complete failure of previous oral health strategies. The differences in methodology between the 1998 and the 2006 surveys were accountable for the difference in DMFT values recorded. Oral health surveys should not be conducted for the sake of surveying, but they should be used in the context of advocacy to address the neglect of oral health. For this, they must include an indicator framework that allows for linkages of the oral health status into the broader sectors of health and development.

\section{P2-500 PSYCHOLOGICAL DISTRESS AND TRAUMATIC DENTAL INJURIES IN ADOLESCENTS FROM EAST LONDON}

\section{doi:10.1136/jech.2011.142976m.27}

${ }^{1}$ E Bernabé, ${ }^{2}$ S Stansfeld, ${ }^{1} \mathrm{~W}$ Marcenes. Institute of Dentistry, Barts and The London, Queen Mary University of London, London, UK; ${ }^{2}$ Wolfson Institute of Preventive Medicine, Barts and The London, Queen Mary University of London, London, UK

Objective To explore the relationship between psychological distress and traumatic dental injuries (TDI) among adolescents.

Methods Phase 3 of Research with East London Adolescents Community Health Survey (RELACHS) collected data in a representative sample of 15-16-year-old adolescents in 2005. RELACHS is a longitudinal secondary school-based epidemiological study that followed up pupils aged 11-12 years in 2001 and 13-14 years in 2003. Adolescents provided information on their demographic characteristics (sex, age and ethnicity), socioeconomic position (parental employment and car ownership), family structure and psychological distress (using the Strength and Difficulties Questionnaire, SDQ). The SDO contains 25 items equally divided into five subscales: hyperactivity, emotional problems, conduct problems, peer problems and pro-social behaviour. Participants were also clinically examined for TDI, overjet and type of lip coverage. Logistic regression models were fitted to test the associations of SDQ and each subscale with TDI.

Results 975 adolescents participated in the study (67.2\% response rate), of whom 886 had information on relevant variables $(56.8 \%$ females and $74.5 \%$ non-White). The prevalence of psychological distress and TDI were $10 \%$ and $16 \%$, respectively. In regression models, being a high scorer on the SDQ was positively related to having TDI (OR: 2.02, 95\% CI 1.11 to 3.70) after adjustment for demographic characteristics, socioeconomic position, family structure and oral clinical characteristics. Analysis by subscales showed that only having peer problems was significantly related to having TDI after adjustment for confounders (OR: 2.18; 95\% CI 1.09 to 4.34).

Conclusion Psychological distress and especially peer problems play an important role in the occurrence of TDI in adolescents.

\section{P2-501 ACCURACY OF SELF-REPORT OF ON-ROAD CRASHES AND TRAFFIC OFFENCES IN A COHORT OF YOUNG DRIVERS: THE DRIVE STUDY}

doi:10.1136/jech.2011.142976m.28

${ }^{1} \mathrm{~S}$ Boufous, ${ }^{*} \mathrm{R}$ Ivers, ${ }^{1} \mathrm{~T}$ Senserrick, ${ }^{1} \mathrm{M}$ Stevenson, ${ }^{1} \mathrm{R}$ Norton, ${ }^{2} \mathrm{~A}$ Williamson. ${ }^{1}$ The George Institute for Global Health, University of Sydney, Sydney, New South Wales, Australia; ${ }^{2}$ Faculty of Science, University of New South Wales, Sydney, New South Wales, Australia

Introduction Road traffic injuries are a leading cause of death and disability worldwide, particularly among young adults. While surveys are widely used to measure the incidence of on-road crashes and offences, little is known about the validity of self-reports of these events, particularly among young drivers. This study examines the accuracy of self-report of on-road crashes and traffic offences among participants in the DRIVE study: a cohort study of 20822 drivers aged 17-24 year-old, recently licensed in New South Wales, Australia.

Methods A total of 2991 DRIVE study participants who completed the follow-up questionnaire, approximately 2 years after joining the study, were asked whether they had been involved in an on-road crash or were convicted for a traffic offence during the year prior to the survey. This information was subsequently linked to police recorded crash and offence data to determine the level of accuracy of these self-reports.

Results Young drivers reported more crashes and traffic offences than those recorded in the police database during the 1-year study period. The findings showed a high level of accuracy in young drivers' self-report of police recorded crashes $(85.1 \%$; $95 \%$ CI $78.2 \%$ to $92.1 \%$ ) and of police recorded traffic offences $(83.0 \%$; $95 \% \mathrm{CI}$ $79.4 \%$ to $86.6 \%$ ).

Conclusions The results suggest that surveys may be useful tools for estimating the incidence of traffic crashes and offences in young drivers. The findings are particularly relevant to countries and jurisdictions where access to administrative data are limited.

\section{P2-502 PREVALENCE OF CHILD SEXUAL ABUSE AMONG WOMEN IN BRAZIL}

doi:10.1136/jech.2011.142976m.29

G B de Castro, ${ }^{*}$ I F Junior, L B Schraiber. Faculdade de Saúde Pública da Universidade de São Paulo, São Paulo, São Paulo, Southeastern, Brazil

Objective To estimate the prevalence of child sexual abuse among women in Brazil.

Methods Data based on a multicenter cross-sectional study performed by WHO. It used cluster sampling, with a representative sample of 1172 women aged 15-49 years in São Paulo, Southeastern Brazil, and 1473 women from Zona da Mata de Pernambuco, Northeastern. Standardised questionnaires were completed in 2000 and 2001. The $\chi^{2}$ test was performed. 